Article

\title{
Complex Permittivity and Electromagnetic Interference Shielding Effectiveness of OPEFB Fiber-Polylactic Acid Filled with Reduced Graphene Oxide
}

\author{
Ismail Ibrahim Lakin ${ }^{1}$, Zulkifly Abbas ${ }^{1, *}$, Rabaah Syahidah Azis ${ }^{1,2}$ (1) \\ and Ibrahim Abubakar Alhaji ${ }^{1}$ \\ 1 Department of Physics, Faculty of Science, University Putra Malaysia (UPM), Serdang 43400, Malaysia; \\ gs51771@student.upm.edu.my (I.I.L.); rabaah@upm.edu.my (R.S.A.); gs54099@student.upm.edu.my (I.A.A.) \\ 2 Material Synthesis and Characterization Laboratory, Institute of Advanced Technology (ITMA), \\ University Putra Malaysia (UPM), Serdang 43400, Malaysia \\ * Correspondence: za@upm.edu.my; Tel.: +60-17-330-0429
}

Received: 22 June 2020; Accepted: 5 August 2020; Published: 16 October 2020

check for updates

\begin{abstract}
This study was aimed at fabricating composites of polylactic acid (PLA) matrix-reinforced oil palm empty fruit bunch (OPEFB) fiber filled with chemically reduced graphene oxide ( $\mathrm{rGO}$ ). A total of 2-8 wt.\% rGO/OPEFB/PLA composites were characterized for their complex permittivity using an open-ended coaxial probe (OEC) technique. The shielding efficiency properties were calculated using the measured transmission $\left(\mathrm{S}_{21}\right)$ and the reflection $\left(\mathrm{S}_{11}\right)$ coefficient results. All the measurements and calculations were performed in the $8-12 \mathrm{GHz}$ frequency range. The morphological and microstructural study included X-ray diffraction (XRD), field emission scanning electron microscopy (FE-SEM), and Fourier transform infrared spectroscopy (FTIR). The results indicated that the incorporation of rGO as filler into the composites enhanced their complex permittivity properties. The composites showed a total shielding efficiency $\left(\mathrm{SE}_{\mathrm{T}}\right)$ of about $31.2 \mathrm{~dB}$ at a frequency range of $8-12 \mathrm{GHz}$, which suggests their usefulness for microwave absorption.
\end{abstract}

Keywords: fiber; polymer; dielectric properties; reduced graphene oxide; EMI shielding effectiveness

\section{Introduction}

In this contemporary world of information technology (IT), we are surrounded by telecommunications and electronic devices, and their use is unavoidable. Electromagnetic interference (EMI) is an unwanted by-product of rapid electronic systems and telecommunication devices. This radiation can result in improper operation of other equipment [1-3]. Efforts have been made to minimize emissions of an electromagnetic nature by using EMI absorbing materials [4]. These materials attenuate signals by absorbing and/or reflecting the radiation energy [5]. Several materials, such as metals, carbon materials (carbon nanotubes, and activated carbons, etc.), and their composites, are excellent candidates for EMI absorbing applications [6,7]. For this purpose, conventional metal shielding materials are used for a long time and serve as the most effective EMI shield. However, they have several drawbacks, such as being corrosive, heavyweight, complicated processing, and additionally shielding is by reflection, which will minimally contribute to the reduction of EM pollution [8].

Conductive polymer composites (CPCs) have attracted both research and industrial interest for many decades due to their high flexibility, wideband electrical conductivity, secure processing, and low cost, which make them promising candidates for EMI shielding applications. They are considered a significant group of relatively cost-effective materials to satisfy a wide range of engineering applications 
such as electrically conductive adhesives, antistatic coatings and films, sensors, electromagnetic and electrical energy storage devices, and an efficient EMI shielding material $[9,10]$. Excellent shielding effectiveness has been reported on CPCs filled with carbon materials such as carbon fibers [11], carbon black [12], carbon nanotubes (CNTs) [13], and graphite [14] in terms of their intrinsic properties such as aspect ratios, electrical conductivities, and dielectric properties. Most commercial polymers, like polyethylene, polypropylene, and polystyrene, are not biodegradable. Polylactic acid (PLA), as thermoplastic polyester, is flexible and is produced mostly from annually renewable materials. PLA has become of high-interest due to its adaptability and suitability in many production techniques such as injection molding, extrusion, and thermoforming.

Moreover, PLA has high strength, elasticity modulus, stiffness, and is a fully biodegradable matrix. The emergence of natural fiber composites has fascinated research attention in recent years because, in terms of weight reduction, fibers can replace conventional reinforcing materials [15]. PLA reinforced with pineapple leaf [16], kenaf [17], oil palm empty fruit bunch fiber (OPEFB) [18], and other natural fibers have been studied.

Recently, different materials with graphene particles were investigated and showed exciting results in electromagnetic absorption. Due to their excellent properties, graphene materials have been used in multifunctional polymer composites as a filler $[19,20]$. Graphene-polymethyl methacrylate microcellular nanocomposite foams showed an EMI shielding effectiveness up to $19 \mathrm{~dB}$ at a frequency range of 8-12 GHz with the help of multiple reflections and scattering incident microwaves into the foam samples [21]. Epoxy resin polymer filled with reduced graphene oxide attained a value of $25.748 \mathrm{~dB}$ at $12 \mathrm{GHz}$ for the $5 \mathrm{wt} . \%$ reduced graphene [22]. PLA/GNP nanocomposites exhibit total Shielding effectiveness $\mathrm{SE}_{\mathrm{T}}$ of 14.6 and $15.5 \mathrm{~dB}$ for PL15 in bands C- and X, respectively [23].

In this study, chemically reduced graphene oxide (rGO) was synthesized. A total of $2-8 \mathrm{wt} . \%$ rGO content was incorporated into the OPEFB/PLA matrix to study the dielectric properties of the composites. EMI shielding performance of rGO/OPEFB/PLA composites was determined in terms of reflection, absorption shielding effectiveness. All the measurements were performed at the $8-12 \mathrm{GHz}$ frequency range. The dielectric measurement of the samples was carried out using the Open-ended coaxial (OEC) probe technique. XRD and FESEM were used to study the physical, chemical, and surface morphology of the composites. The $8 \%$ rGO composite gave an optimum $\left(S E_{T}\right)$ value of $31.2 \mathrm{~dB}$, which is suitable for EMI shielding.

\section{Material and Methods}

\subsection{Materials}

OPEFB fiber was obtained from, Dengkil, Selangor, Malaysia. PLA was bought under the trade name polylactide resin 3052D from nature works LLC (Minnetonka, MN, USA). Graphite powder and reduced graphene oxide $(\mathrm{rGO})$ (synthesized using ammonia $\left(\mathrm{NH}_{3}\right)$ as a reducing agent obtained from Sigma Aldrich (Sarasota, FL, USA)).

\subsection{Synthesis of $r G O$}

The Staudenmaier method was used to synthesize Graphite Oxide (GO) [20]. The reduction of GO to rGO was carried out by putting approximately $400 \mathrm{mg}$ of GO into a thimble for cellulose extraction $30 \mathrm{~mm} \times 100 \mathrm{~mm}$ and then put in the extraction unit Soxhlet. $150 \mathrm{~mL}$ of $30 \%\left(\mathrm{NH}_{3}\right)$ solution, which served as a reducing agent, was used. The sample was heated set at $80^{\circ} \mathrm{C}$ for an exposure time of $6 \mathrm{~h}$. The synthesis process is presented in Figure 1. 


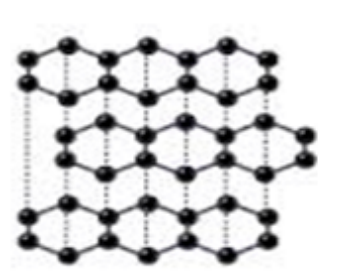

Graphite

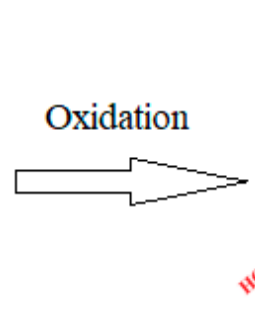

Graphene Oxide

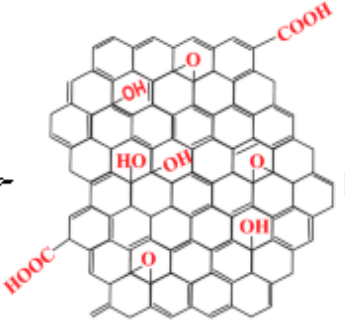

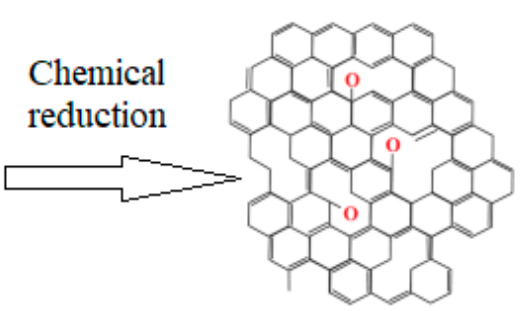

Reduced Graphene Oxide

Figure 1. rGO fabrication route.

\subsection{Fabrication of $r G O / O P E F B / P L A$ Composites}

The OPEFB fibers were soaked in distilled water for $24 \mathrm{~h}$ to remove the wax layer of fibers. The fibers were rinsed with acetone and dried in an oven at $80^{\circ} \mathrm{C}$ for $6 \mathrm{~h}$ to reduce the moisture. The dried fibers were crushed into powder using a crusher machine (Model JL1000-55, JLNE, Jiangsu, China), which was then sifted $100 \mu \mathrm{m}$ by a laboratory sieve (Endecotts, London, UK). The rGO/OPEFB/PLA composites were manufactured by mixing $2 \%, 4 \%, 6 \%$, and $8 \%$ mass percentages of rGO with OPEFB fiber and PLA at a fixed mass ratio of 3:7. The PLA was melted in Brabenda Internal Mixer (Model 815651, $\mathrm{GmbH} \& \mathrm{CO}$. KG, Duisburg, Germany) for $2 \mathrm{~min}$ then the OPEFB followed by the rGO powders were added and continued blending for another $12 \mathrm{~min}$ at $160^{\circ} \mathrm{C}$ with $50 \mathrm{rpm}$ of rotor speed. The composites samples were compressed separately to a thickness of $6 \mathrm{~mm}$, with a hydraulic press (Fred S. Carver part No.:973110A, Wabash, IN, USA) in sample holders at 4 tons, to eliminate air gaps inside the sample likely to influence the results. Figure 2 shows the fabrication of rGO/OPEFB/PLA composites process.

PLA

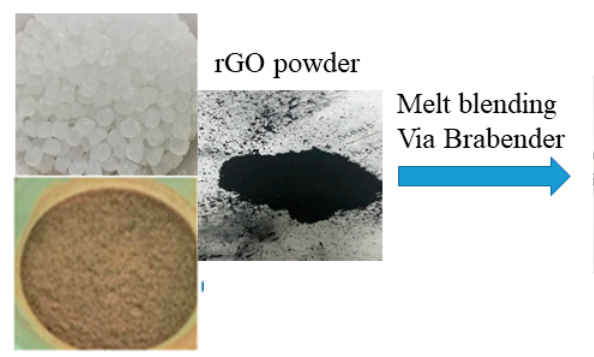

OPEFB fiber

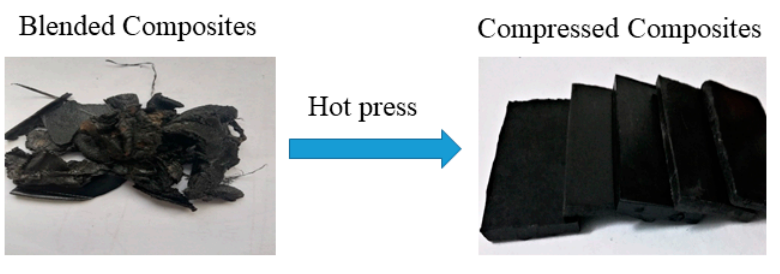

Figure 2. Fabrication of rGO/OPEFB/PLA composites.

\subsection{Characterization}

\subsubsection{Structure and Composition}

Field Emission Scanning Electron microscopy (FE-SEM) was used to examine the morphology of rGO/OPEFB/PLA composites. For morphological characterization, the Nova NanoSEM (FEI, Eindhoven, The Netherlands) operated at an accelerating voltage of $20 \mathrm{kV}$ was used. Samples were put over a carbon tape on the stub for scanning. The gold coating was applied to the sample. X-ray diffraction (XRD) measurement was conducted through a Shimadzu XRD 600 diffractometer (Tokyo, Japan) with a nickel-filtered $\mathrm{Cu}-\mathrm{K} \alpha(\alpha=0.1542 \mathrm{~nm})$ beam performed at $30 \mathrm{kV}$ voltage and $30 \mathrm{~mA}$ current. The composites were scanned within the range of scattering angles of $2 \theta$ of $10^{\circ}$ to $80^{\circ}$ at the rate of $2 \%$ min. Fourier transforms infrared (FTIR) analysis was carried out through the Perkin Elmer Model 100 series (Waltham, MA, USA). The samples were registered in the wavenumber range from 400 to $4000 \mathrm{~cm}^{-1}$. 


\subsubsection{Dielectric Properties}

The measurements for the complex permittivity of the composites were carried out using the OEC probe HP85071C technique (Agilent, Santa Clara, CA, USA). The probe was connected to an HP8720B Vector Network Analyzer (VNA) via a high-precision coaxial test cable [24]. The OEC probe is particularly suited for the measurements of complex permittivity of liquid. It can be used for solid but special attention should be paid concerning samples flatness and the contact between the sample and the probe. A standard one-port, short-air-water calibration was performed, and a reference standard material (polytetrafluoroethylene) was characterized to validate the accuracy of the calibration. As illustrated in Figure 3, the OEC probe was then firmly positioned on the flat surface of the powdered samples to determine complex permittivity using the software installed on the VNA. All the measurements were performed in the $8-12 \mathrm{GHz}$ frequency range.

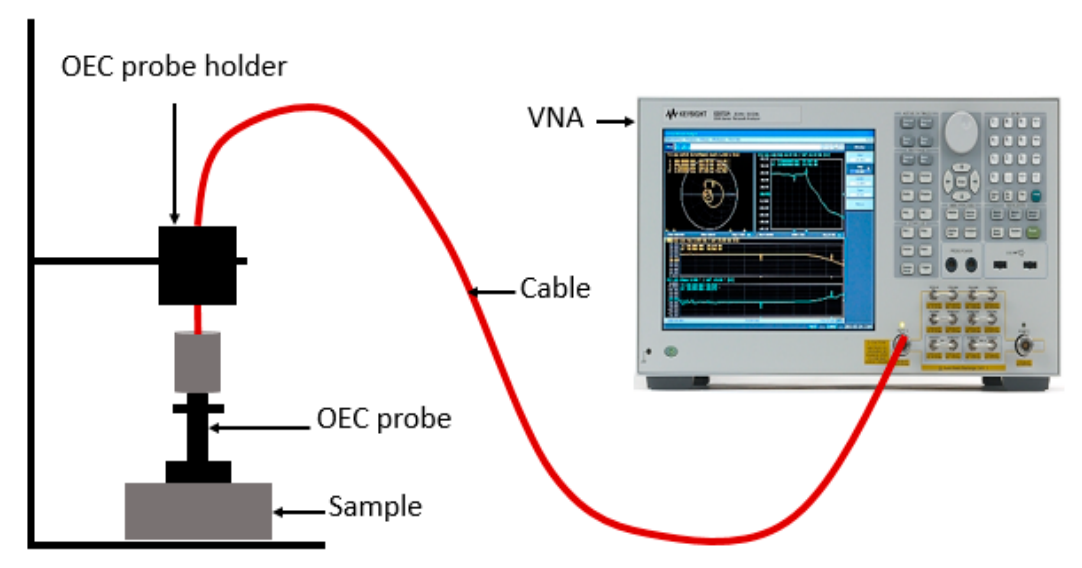

Figure 3. Complex permittivity measurement using OEC.

\subsubsection{Shielding Effectiveness}

The combined result of attenuation due to absorption, reflection, and multiple internal reflection losses at the interfaces of a material, encountered by incident EM wave is known as total shielding effectiveness $\left(S E_{T}\right)$ and can be given as:

$$
S E_{T}=\left(S E_{R}+S E_{A}+S E_{M}\right)
$$

A two-port VNA reflected and transmitted wave, also known as S-parameters $\left(S_{11}\right.$ and $\left.S_{21}\right)$, is related to reflectance $\left(\left|S_{11}\right|^{2}\right)$, transmittance $\left(\left|S_{21}\right|^{2}\right)$, and absorbance $(A=1-R-T)$. The shielding performance is calculated by the logarithmic proportion of incident and transmitted EM radiation, and can be expressed [25] as:

$$
\begin{gathered}
S E_{A}=10 \log _{10}\left(\frac{1-R}{T}\right)=10 \log _{10}\left(\frac{1-\left|S_{11}\right|^{2}}{\left|S_{21}\right|^{2}}\right) \\
S E_{R}=10 \log _{10}\left(\frac{1}{1-R}\right)=10 \log _{10}\left(\frac{1}{1-\left|S_{11}\right|^{2}}\right) \\
S E_{T}=10 \log _{10}\left(\frac{1}{T}\right)=10 \log _{10}\left(\frac{1}{\left|S_{21}\right|^{2}}\right)
\end{gathered}
$$




\section{Results and Discussion}

\subsection{Field Emission Scanning Electron Microscopy}

FE-SEM images were analyzed for blend morphology and additive distribution. The FE-SEM results for the $\mathrm{rGO}$ and the $\mathrm{rGO} / \mathrm{OPEFB} / \mathrm{PLA}$ substrates at various $\mathrm{rGO}$ contents $(2 \%, 4 \%$, and $8 \% \mathrm{rGO})$ are presented in Figure 4. It is observed that (Figure 4a) the rGO is irregular, and has many folded layers at the edges [26]. The flake-like layers are continuously cross-linked in a brittle textured form without any other crystallized particle phase [27]. The $2 \mathrm{wt} . \%$ of rGO was homogeneously dispersed in the PLA reinforced OPEFB fiber composite (Figure 4b). The rGO dispersion (Figure 4c,d) indicates a significant difference between the $4 \%$ and $8 \%$ percentage rGO. It is observed that (Figure $4 \mathrm{~d}$ ) the rGO filler was distributed in the OPEFB/PLA matrix in which the irregular, wrinkled, and folded layered at the edges features of rGO powder resurfaces. The morphological figures indicate that rGO filler did react with the OPEFB/PLA substrates.
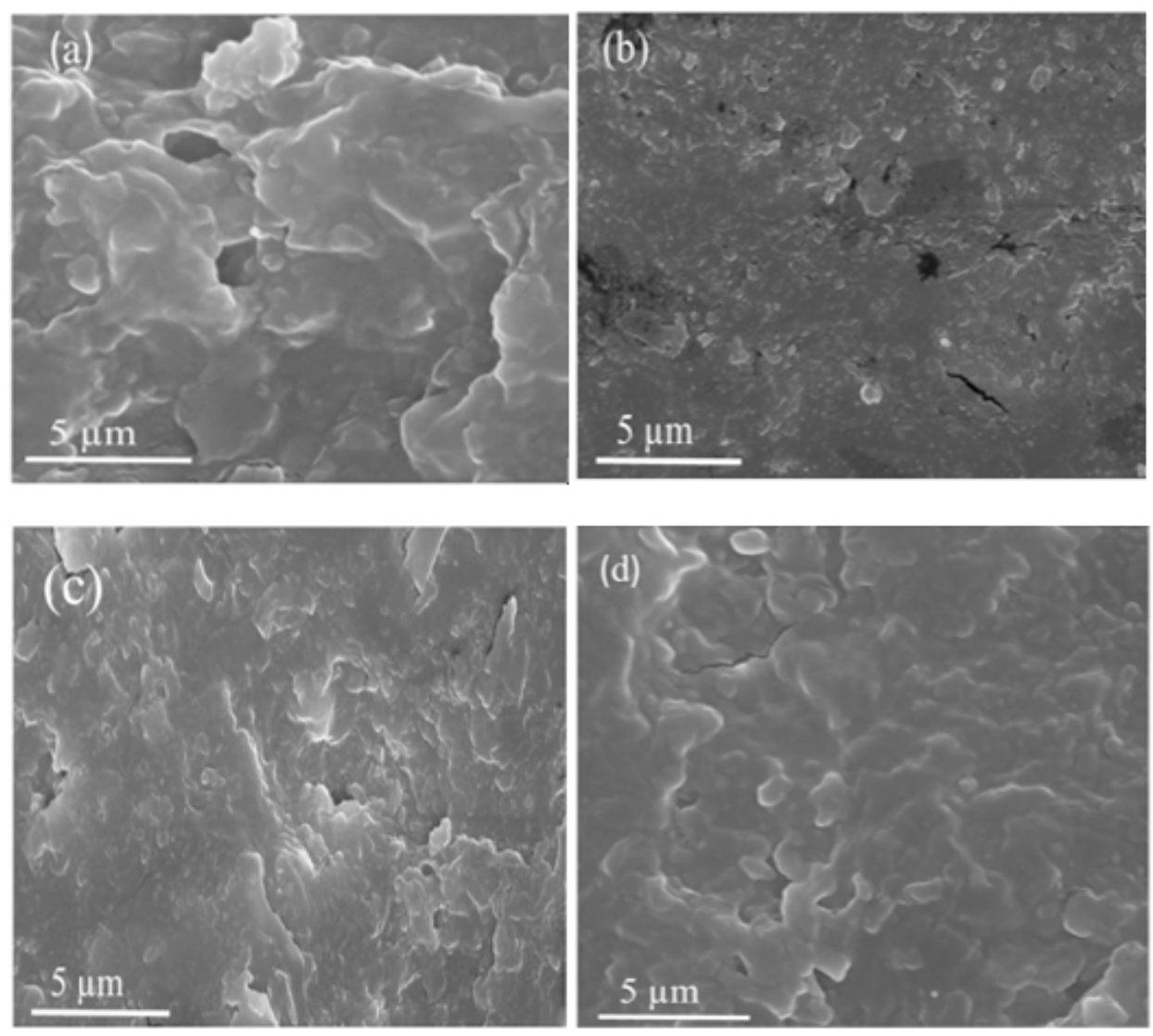

Figure 4. FE-SEM micrographs of (a) rGO, (b) 2 wt.\%, (c) 4 wt.\%, and (d) 8 wt.\% rGO fillers.

\subsection{X-ray Diffraction}

XRD diffractograms of rGO, OPEFB/PLA, and rGO/OPEFB/PLA composites are presented in Figure 5. The XRD patterns of pure OPEFB/PLA showed a broad diffraction peak at approximately $2 \theta \approx 17.42^{\circ}$ to $30.21^{\circ}$. The OPEFB/PLA showed no characteristic peak, which indicates that PLA [28] and OPEFB [29] has an amorphous structure. The broad peaks of OPEFB/PLA suggest carbon-based and cellulose type material [18]. The XRD spectra of the reduced rGO had several diffraction peaks at $2 \theta \approx 18.85^{\circ}, 39.06^{\circ}, 42.67^{\circ}, 45.74^{\circ}$, and $73.27^{\circ}$ parts corresponding to the $(002),(100),(101),(102)$, and (004) hexagonal carbon structure, respectively (JCPDS no. 19-0629) [30]. The highest peak of rGO appeared at $45.74^{\circ}$, indicating a high degree of crystallinity. It is observed that with the addition of 2-8 wt.\% rGO, the intensity of the OPEFB/PLA matrix increased significantly, which in turn increased 
the composite crystallinity. This increase can be attributed to rGO nucleating effect in PLA [23]. The rGO/OPEFB/PLA composites with $2 \%, 4 \%, 6 \%$, and $8 \%$ rGO contents also exhibit the highest diffraction peaks at $2 \theta \approx 73.16^{\circ}, 45.39^{\circ}, 45.70^{\circ}$ and $45.94^{\circ}$, respectively.

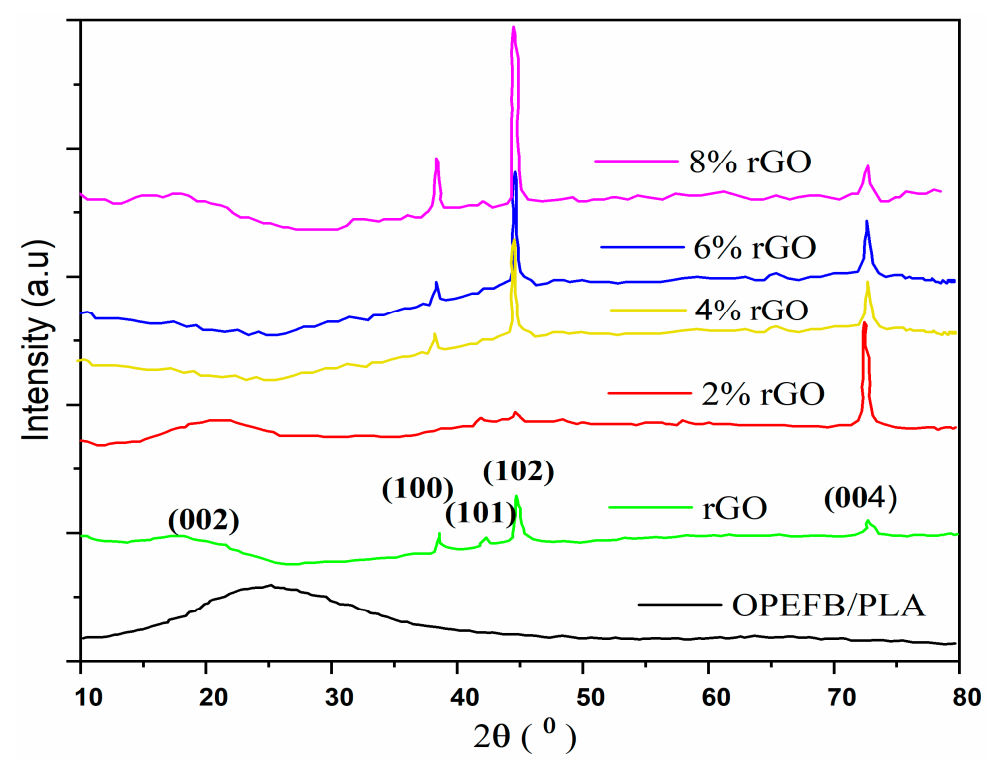

Figure 5. XRD patterns of OPEFB/PLA, rGO, and $\mathrm{rGO} / \mathrm{OPEFB} / \mathrm{PLA}$ at various percentages of $\mathrm{rGO}$ filler.

\subsection{Fourier Transform Infrared}

The FTIR spectra for OPEFB fiber, PLA, rGO, and OPEFB/PLA matrix filled with various $(2 \%, 4 \%, 6 \%$, and $8 \%)$ percentages of rGO is shown in Figure 6. The characteristic band at $2991 \mathrm{~cm}^{-1}$ to $2976 \mathrm{~cm}^{-1}$ corresponds to $\mathrm{C}-\mathrm{H}$ stretching vibrations, $1652 \mathrm{~cm}^{-1}$ (C=C skeletal vibration), $1521 \mathrm{~cm}^{-1}$ (C-C stretching), $1121 \mathrm{~cm}^{-1}$ (C-O-C stretching), and $874 \mathrm{~cm}^{-1}$ (C=O stretching) [31]. Furthermore, the absorption bands at $1343 \mathrm{~cm}^{-1}$ to $1419 \mathrm{~cm}^{-1}$ correspond to $\mathrm{C}-\mathrm{OH}$ stretching, $2927 \mathrm{~cm}^{-1} \mathrm{C}-\mathrm{H}$ stretching, and $3395 \mathrm{~cm}^{-1}$ (O-H vibration) [32]. A shift in characteristic bands $\left(1754 \mathrm{~cm}^{-1}\right)$ is noticed in the FTIR spectra when the composite particles have a strong interaction. These characteristics strongly demonstrate the existence of functional carbonyl and carboxylic groups on the rGO flakes surface [33].

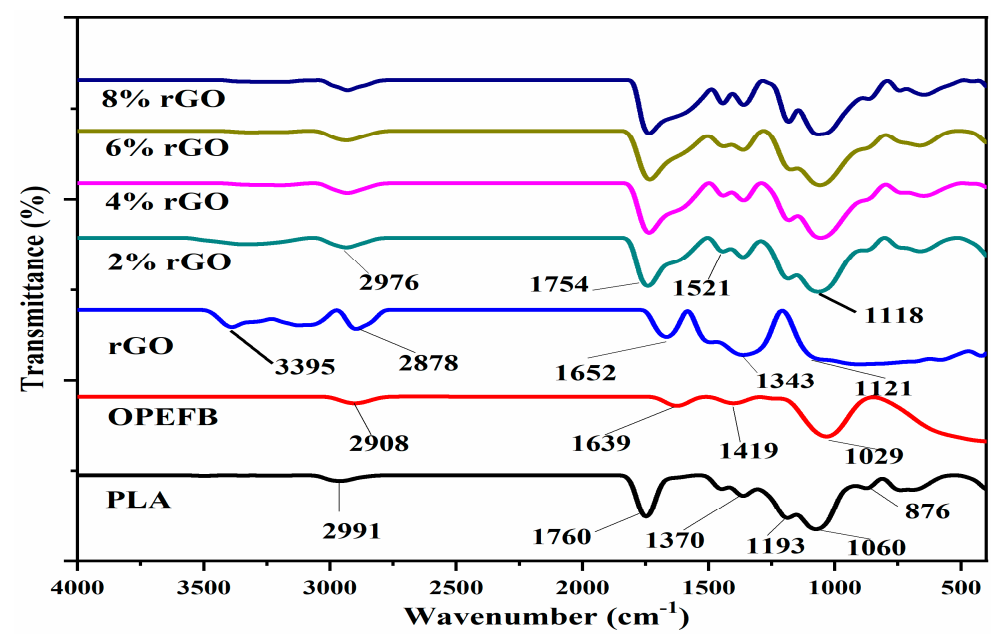

Figure 6. FTIR of OPEFB fiber, PLA, rGO, and rGO/OPEFB/PLA at various percentages of rGO loadings. 


\subsection{Dielectric Properties}

The significant impacts that occur upon the interaction between a dielectric material and electric field are: surface transmittance, energy absorbance, and energy reflection. These impacts help to show the electrical properties associated with the relative permittivity. To analyze the dielectric properties of the OPEFB fiber, PLA, OPEFB/PLA matrix, and rGO/OPEFB/PLA composites compressed substrates were characterized for their real $\left(\varepsilon^{\prime}\right)$ and imaginary $\left(\varepsilon^{\prime \prime}\right)$ parts of the relative complex permittivity $\left(\varepsilon^{*}=\varepsilon^{\prime}-j \varepsilon^{\prime \prime}\right)$ at $8-12 \mathrm{GHz}$ frequency range. Figure 7 shows the dielectric properties for the OPEFB fiber, PLA, OPEFB/PLA matrix. PLA has low complex permittivity due to the low polarization of the macromolecules. Adding fillers to the polymer will substantially boost the matrix's low permittivity [18] since the polarization of filler/polymer interfaces (interfacial polarization), and filler can significantly contribute to the overall polarization of the composite. For all the samples, $\varepsilon^{\prime}$ and $\varepsilon^{\prime \prime}$ decreased as the frequency increased. The OPEFB fiber had the highest values of $\varepsilon^{\prime}$ and $\varepsilon^{\prime \prime}$ of 3.63 and 0.64 at $8 \mathrm{GHz}$, then slowly decreased to 3.48 and 0.59 at $12 \mathrm{GHz}$. The PLA had $\varepsilon^{\prime}$ and $\varepsilon^{\prime \prime}$ values of 2.74 and 0.09 at $8 \mathrm{GHz}$, later reduced to 2.66 and 0.05 at $12 \mathrm{GHz}$. The OPEFB/PLA matrix also shows the same pattern where the values of $\varepsilon^{\prime}$ and $\varepsilon^{\prime \prime}$ at $8 \mathrm{GHz}$ were found to be 3.01 and 0.31 , then decreased to 2.94 and 0.96 at $12 \mathrm{GHz}$, respectively. A reduction in the orientation polarization at high frequencies resulted in a decrease in the $\varepsilon^{\prime}$ corresponding to the frequency [34].

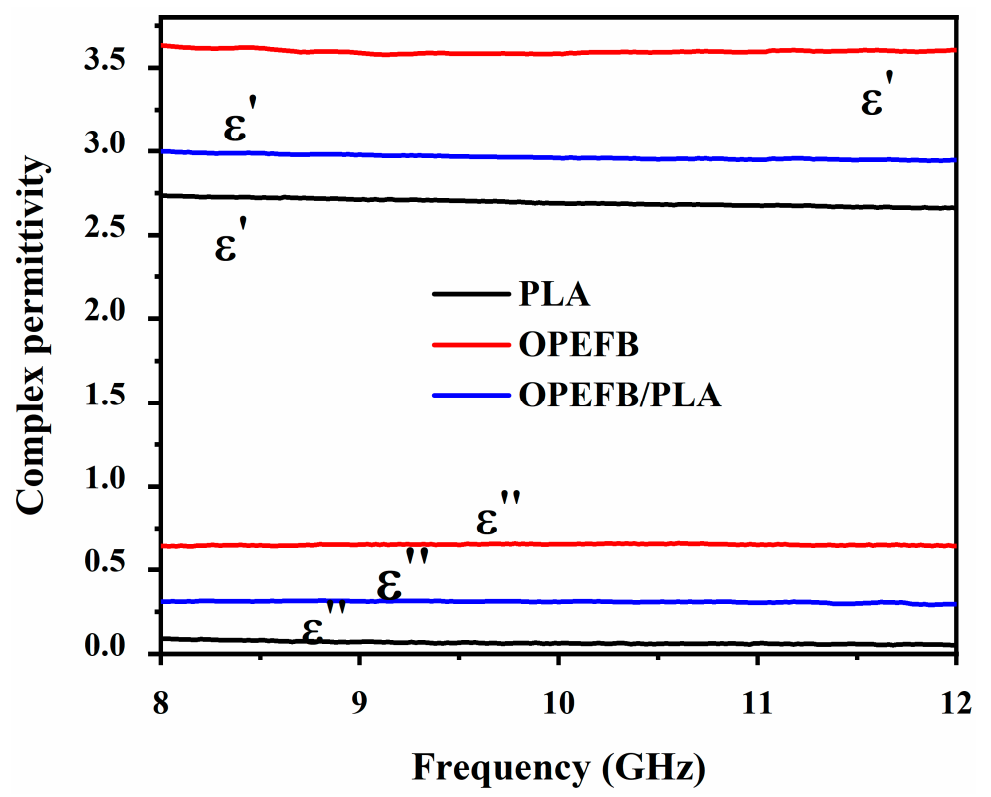

Figure 7. The variation of dielectric properties of OPEFB, PLA, and OPEFB/PLA composite with frequency.

The effect of the $2-8 \%$ rGO filler loadings on the dielectric permittivity of rGO/OPEFB/PLA composites was studied, and the variation in $\varepsilon^{\prime}$ and $\varepsilon^{\prime \prime}$ values in the 8-12 GHz range are shown in Figure $8 \mathrm{a}, \mathrm{b}$. The real $\left(\varepsilon^{\prime}\right)$ and imaginary $\left(\varepsilon^{\prime \prime}\right)$ parts of the complex permittivity decreased as the frequency increased. The result showed that the microwave electric field affected the interaction of $\mathrm{rGO} / \mathrm{OPEFB} / \mathrm{PLA}$ composites with electromagnetic waves. Once the microwave frequency was raised, an electric field was generated that varied continuously. The various electrical field created polarization in the composites. Dipole moment slowly decreased in composites as frequency increased. Also, the dipole had a lesser duration to realign to the oscillating electric field [35]. $\varepsilon^{\prime}$ and $\varepsilon^{\prime \prime}$ values of the composites increased with higher loadings of rGO contents throughout the investigated frequency range. It can be seen that the least $\varepsilon^{\prime}$ (3.38) was measured for the $\%$ rGO filler, whereas the highest $\varepsilon^{\prime}$ (3.60) was measured for the $8 \%$ rGO filler. Also, the lowest $\varepsilon^{\prime \prime}(0.36)$ was obtained from the $2 \%$ rGO filler, whereas the highest $\varepsilon^{\prime \prime}(0.45)$ was measured for the $8 \%$ rGO filler. The increment of the dielectric properties can be attributed to interfacial polarization. The $\varepsilon^{\prime}$ of $\mathrm{rGO} / \mathrm{OPEFB} / \mathrm{PLA}$ composite is higher 
than the OPEFB/PLA matrix composite, which is attributed to widely available rGO polarization defects and interfacial polarization caused by OPEFB/PLA and rGO interface coupling [36]. The distribution of rGO particles was low at $2 \%$ rGO; therefore, their interaction with the OPEFB/PLA matrix is weak. When the concentration of rGO filler increases, the particles' interaction within the matrix increased. The average polarization correlated with a cluster of particles is more robust than an individual particle due to improved composite inclusion dimensions and thus greater interfacial area [37], this results in higher average polarization, and hence, a higher contribution to the dielectric properties. However, it is observed that even at $8 \% \mathrm{rGO}$, the obtained permittivity values were lower than values obtained by Kashi et al. [38], where $\varepsilon^{\prime}$ and $\varepsilon^{\prime \prime}$ attained values of 11.17 and 0.87 , respectively, for $6 \%$ GNP. A significant permittivity value difference attributed to the dispersion state of fillers in the matrix, which in turn depends on the affinity and interactions between the fillers and the polymer [39].

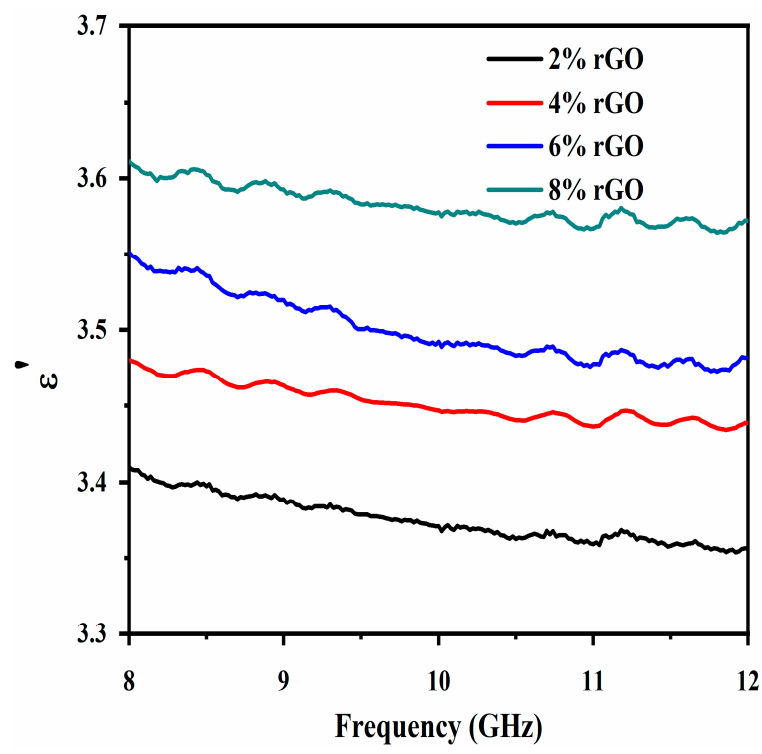

(a)

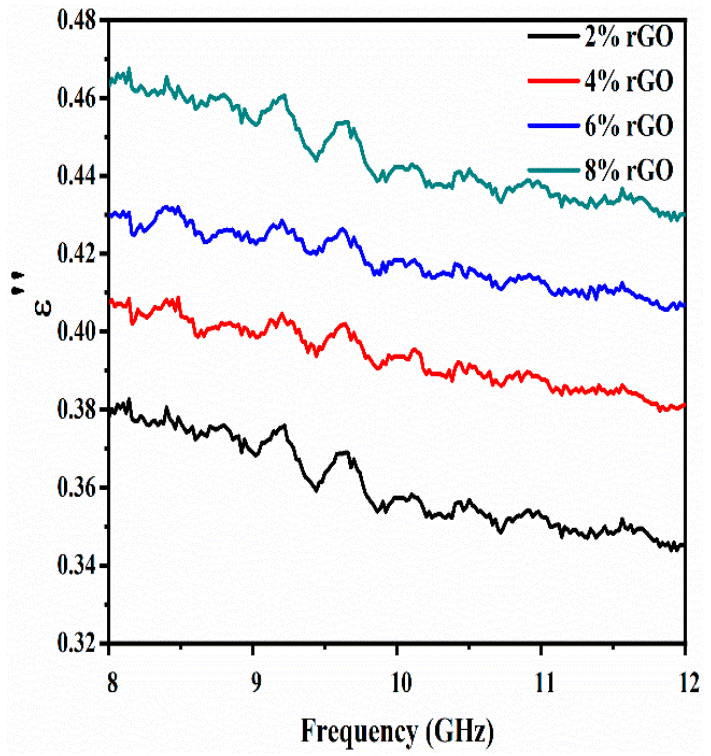

(b)

Figure 8. (a) Dielectric constant and (b) loss factor of rGO/OPEFB/PLA composites.

The $\varepsilon^{\prime \prime}$ part of the permittivity represents the energy dissipation. The grain boundaries had high resistivity at low frequencies and, due to the aggregation of electrons at the grain boundaries, a higher energy acquisition was needed for electron hopping, resulting in higher electrical energy loss. Conversely, the grain boundaries had low resistivity at high frequencies and thus less loss of electrical energy from electron hopping [40].

\subsection{Shielding Effectiveness}

Figure $9 \mathrm{a}-\mathrm{c}$ presents the frequency variation of $\mathrm{rGO} / \mathrm{OPEFB} / \mathrm{PLA}$ composite EMI shielding responses in the $8-12 \mathrm{GHz}$ frequency range. Figure 9a reveals that the values of $\mathrm{SE}_{\mathrm{A}}$ for the $\mathrm{rGO} / \mathrm{OPEFB} / \mathrm{PLA}$ composites increased significantly in frequency. The $\mathrm{SE}_{\mathrm{A}}$ values of $6 \% \mathrm{rGO}$ composites, for example, increased from $16.0 \mathrm{~dB}$ at $8 \mathrm{GHz}$ to $20.8 \mathrm{~dB}$ at $12 \mathrm{GHz}$, whereas $\mathrm{SE}_{\mathrm{R}}$ decreased from $5.2 \mathrm{~dB}$ at $8 \mathrm{GHz}$ to $4.4 \mathrm{~dB}$ at $12 \mathrm{GHz}$ as depicted in Figure $9 \mathrm{~b}$. It is also noteworthy that $\mathrm{SE}_{\mathrm{A}}$ increases as $\mathrm{rGO}$ increased, and this result can be ascribed to the conductive mesh refinement. As the content of rGOs increases, their intercept with the polymer matrix increased, which leads to improvement of polarization and, therefore, absorbance. This can be attributed to the electron motion hysteresis under an alternating EM field, induced additional polarization relaxation processes that helped improve microwave absorption attenuation [41]. 


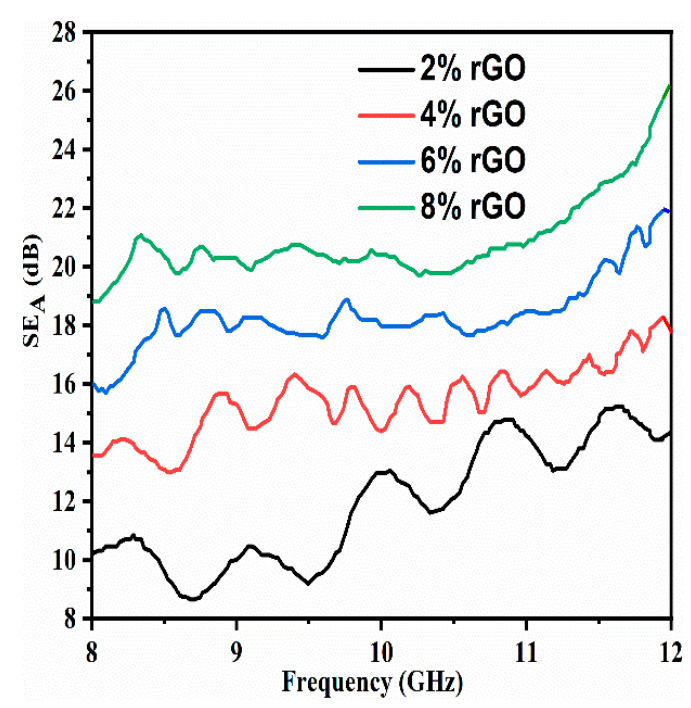

(a)

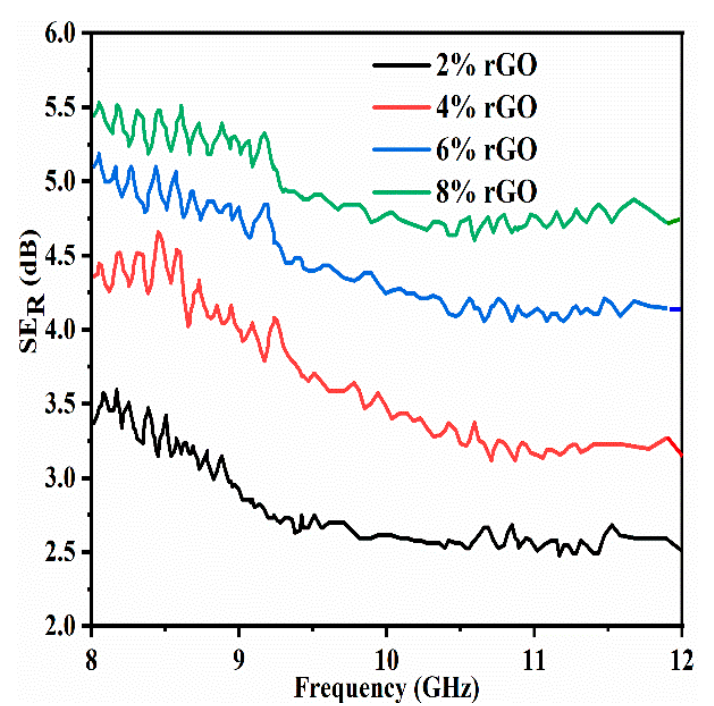

(b)

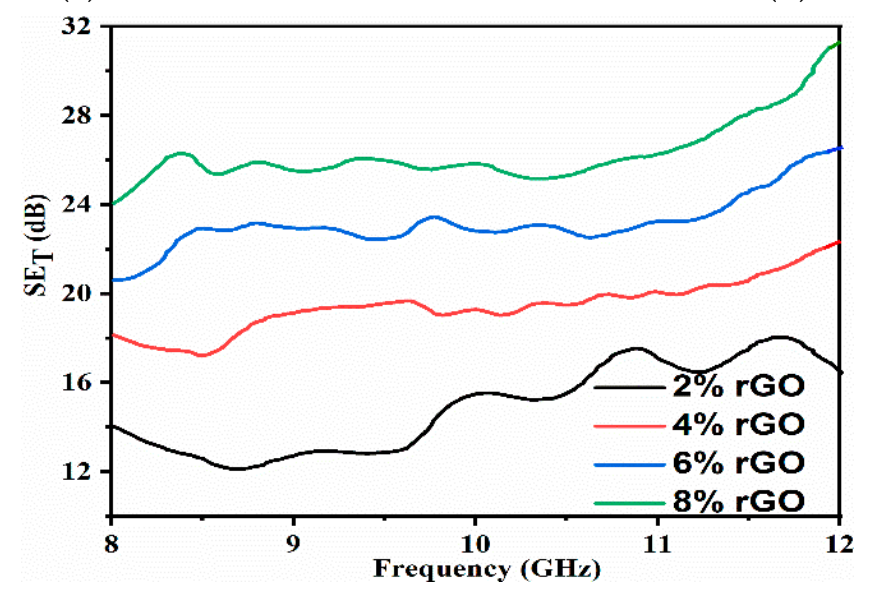

(c)

Figure 9. Variation of rGO/OPEFB/PLA composites (thickness of $6 \mathrm{~mm}$ ) due to (a) absorption, (b) to reflection and, (c) total EMI shielding.

Figure 9c illustrates the $\mathrm{SE}_{\mathrm{T}}$ of $\mathrm{rGO} / \mathrm{OPEFB} / \mathrm{PLA}$ composites. The results indicate that the addition of rGO enhanced the composites' EMI shielding property, which increased with the rGO content increase. The increased polarity of all composites attributed to the rise in rGO filler concentration, which resulted in the enhancement of the shielding capacity by large numbers of mobile charging carriers, making the interaction with an external EM field easier. Moreover, the frequency dependence of $\mathrm{SE}_{\mathrm{T}}$ is observed for a highly filled PLA matrix that exhibits a decreasing trend with increasing frequency. Similar behavior on other filled polymers was observed [42]. The summary of $\mathrm{SE}_{\mathrm{T}}(\mathrm{dB})$ values of OPEFB/PLA matrix filled with $2 \%, 4 \%, 6 \%$, and $8 \%$ rGO content at some selected frequencies such as $8,10,12 \mathrm{GHz}$ is presented in Table 1 .

Table 1. Variation in $\mathrm{SE}_{\mathrm{T}}(\mathrm{dB})$ at specified frequencies.

\begin{tabular}{ccccc}
\hline Frequency $(\mathrm{GHz})$ & $\mathbf{2 \%}$ & $\mathbf{4 \%}$ & $\mathbf{6 \%}$ & $\mathbf{8 \%}$ \\
\hline 8 & 12.7 & 17.9 & 22.5 & 25.4 \\
10 & 15.6 & 19.6 & 22.9 & 26.1 \\
12 & 16.1 & 21.3 & 26.4 & 31.2 \\
\hline
\end{tabular}




\section{Conclusions}

In this study, chemically reduced graphene oxide (rGO) was synthesized from graphite powder using an ammonia solution method. The rGO was used as filler in PLA matrix reinforced with $100 \mu \mathrm{m}$ OPEFB fiber to fabricate rGO/OPEFB/PLA composites, which enhanced complex permittivity values and excellent shielding effectiveness properties with increased filler content. The rGO/OPEFB/PLA composites were characterized for their dielectric properties at 8 to $12 \mathrm{GHz}$ frequency range. The $\varepsilon^{\prime}$ and $\varepsilon^{\prime \prime}$ values of all the composites increased with increase in rGO content. The higher attenuation due to absorption and reflection $(25.9 \mathrm{~dB}$ and $5.49 \mathrm{~dB})$ was obtained for the composite filled with $8 \mathrm{wt} . \%$ rGO content. A maximum $\mathrm{SE}_{\mathrm{T}}$ value of $31.2 \mathrm{~dB}$ was achieved for the composite with $8 \% \mathrm{rGO}$ filler. The markedly enhanced $\mathrm{SE}_{\mathrm{T}}$ obtained with the addition of OPEFB fiber is a promising new and secure method for the application of rGO-filled composites to microwave absorbing applications. The study reveals that $\mathrm{rGO} / \mathrm{OPEFB} / \mathrm{PLA}$ composites are potential candidates for EMI shielding applications in the area where lightweight material is required.

Author Contributions: Conceptualization, Z.A. and R.S.A.; methodology, I.I.L., Z.A. and I.A.A.; investigation, I.I.L. and Z.A.; writing - original draft, I.I.L.; resources, R.S.A.; Formal analysis Z.A. and I.A.A. All authors have read and agreed to the published version of the manuscript.

Funding: This work was supported by Universiti Putra Malaysia Grants (Putra initiative Grants (UPM/700-1/2/GPPI/2017/954160)), Impact Putra Grants (GP-IPS/2017/9580600) and the Ministry of Education Malaysia (Fundamental Research Grants Scheme (FRGS) (No. 5524942).

Conflicts of Interest: The authors declare that there are no conflicts of interest regarding the publication of this paper. The funders had no role in the design of the study; in the collection, analyses, or interpretation of data; in the writing of the manuscript, or in the decision to publish the results.

\section{References}

1. Wang, L.L.; Tay, B.K.; See, K.Y.; Sun, Z.; Tan, L.K.; Lua, D. Electromagnetic interference shielding effectiveness of carbon-based materials prepared by screen printing. Carbon 2009, 47, 1905-1910. [CrossRef]

2. Engels, S.; Schneider, N.L.; Lefeldt, N.; Hein, C.M.; Zapka, M.; Michalik, A.; Elbers, D.; Kittel, A.; Hore, P.J.; Mouritsen, $\mathrm{H}$. Anthropogenic electromagnetic noise disrupts magnetic compass orientation in a migratory bird. Nature 2014, 509, 353-356. [CrossRef] [PubMed]

3. Hamzany, Y.; Feinmesser, R.; Shpitzer, T.; Mizrachi, A.; Hilly, O.; Hod, R.; Bahar, G.; Otradnov, I.; Gavish, M.; Nagler, M.G. Is Human Saliva an Indicator of the Adverse Health Effects of Using Mobile Phones? Mary Ann Liebert: New York, NY, USA, 2013.

4. Choudary, V.; Dhawan, S.K.; Saini, P. Polymer based nanocomposites for electromagnetic interference (EMI) shielding. In EMI Shielding Theory and Development of New Materials; Research Signpost: Kerala, India, 2012; pp. 67-100.

5. Thomassin, J.M.; Jerome, C.; Pardoen, T.; Bailly, C.; Huynen, I.; Detrembleur, C. Polymer/carbon-based composites as electromagnetic interference (EMI) shielding materials. Mater. Sci. Eng. R Rep. 2013, 74, 211-232. [CrossRef]

6. Verma, M.; Chauhan, S.S.; Dhawan, S.K.; Choudhary, V. Graphene nanoplatelets/carbon nanotubes/polyurethane composites as efficient shield against electromagnetic polluting radiations. Compos. Part B Eng. 2017, 120, 118-127. [CrossRef]

7. Bagotia, N.; Choudhary, V.; Sharma, D.K. Synergistic effect of graphene/multiwalled carbon nanotube hybrid fillers on mechanical, electrical and EMI shielding properties of polycarbonate/ethylene methyl acrylate nanocomposites. Compos. Part B Eng. 2019, 159, 378-388. [CrossRef]

8. Ravindren, R.; Mondal, S.; Nath, K.; Das, N.C. Prediction of electrical conductivity, double percolation limit and electromagnetic interference shielding effectiveness of copper nanowire filled flexible polymer blend nanocomposites. Compos. Part B Eng. 2019, 164, 559-569. [CrossRef]

9. Bagotia, N.; Choudhary, V.; Sharma, D.K. A review on the mechanical, electrical and EMI shielding properties of carbon nanotubes and graphene reinforced polycarbonate nanocomposites. Polym. Adv. Technol. 2018, 29, 1547-1567. [CrossRef] 
10. Huang, J.; Zhu, Y.; Xu, L.; Chen, J.; Jiang, W.; Nie, X. Massive enhancement in the thermal conductivity of polymer composites by trapping graphene at the interface of a polymer blend. Compos. Sci. Technol. 2016, 129, 160-165. [CrossRef]

11. Cao, M.S.; Song, W.L.; Hou, Z.L.; Wen, B.; Yuan, J. The effects of temperature and frequency on the dielectric properties, electromagnetic interference shielding and microwave-absorption of short carbon fiber/silica composites. Carbon 2010, 48, 788-796. [CrossRef]

12. Im, J.S.; Kim, J.G.; Lee, Y.S. Fluorination effects of carbon black additives for electrical properties and EMI shielding efficiency by improved dispersion and adhesion. Carbon 2009, 47, 2640-2647. [CrossRef]

13. Kuang, T.; Chang, L.; Chen, F.; Sheng, Y.; Fu, D.; Peng, X. Facile preparation of lightweight high-strength biodegradable polymer/multi-walled carbon nanotubes nanocomposite foams for electromagnetic interference shielding. Carbon 2016, 105, 305-313. [CrossRef]

14. Goyal, R.K.; Kadam, A. Polyphenylene sulphide/graphite composites for EMI shielding applications. Adv. Mater. Lett. 2010, 1, 143-147. [CrossRef]

15. Kumar, K.P.; Sekaran, A.S.J. Some natural fibers used in polymer composites and their extraction processes: A review. J. Reinf. Plast. Compos. 2014, 33, 1879-1892. [CrossRef]

16. Challabi, A.J.H.; Chieng, B.W.; Ibrahim, N.A.; Ariffin, H.; Zainuddin, N. Effect of Superheated Steam Treatment on the Mechanical Properties and Dimensional Stability of PALF/PLA Biocomposite. Polymers 2019, 11, 482. [CrossRef] [PubMed]

17. Huda, M.S.; Drzal, L.T.; Mohanty, A.K.; Misra, M. Effect of fiber surface-treatments on the properties of laminated biocomposites from poly (lactic acid) (PLA) and kenaf fibers. Compos. Sci. Technol. 2008, 68, 424-432. [CrossRef]

18. Abdalhadi, D.M.; Abbas, Z.; Ahmad, A.F.; Matori, K.A.; Esa, F. Controlling the Properties of OPEFB/PLA Polymer Composite by Using $\mathrm{Fe}_{2} \mathrm{O}_{3}$ for Microwave Applications. Fibers Polym. 2018, 19, $1513-1521$. [CrossRef]

19. Ferreira, W.H.; Dahmouche, K.; Andrade, C.T. Tuning the mechanical and electrical conductivity properties of graphene-based thermoplastic starch/poly (lactic acid) hybrids. Polym. Compos. 2019, 40, E1131-E1142. [CrossRef]

20. Huang, H.D.; Ren, P.G.; Xu, J.Z.; Xu, L.; Zhong, G.J.; Hsiao, B.S.; Li, Z.M. Improved barrier properties of poly (lactic acid) with randomly dispersed graphene oxide nanosheets. J. Membr. Sci. 2014, 464, 110-118. [CrossRef]

21. Zhang, H.B.; Yan, Q.; Zheng, W.G.; He, Z.; Yu, Z.Z. Tough graphene-Polymer microcellular foams for electromagnetic interference shielding. ACS Appl. Mater. Interfaces 2011, 3, 918-924. [CrossRef]

22. Ahmad, A.F.; Ab Aziz, S.; Abbas, Z.; Obaiys, S.J.; Khamis, A.M.; Hussain, I.R.; Zaid, M.H.M. Preparation of a chemically reduced graphene oxide reinforced epoxy resin polymer as a composite for electromagnetic interference shielding and microwave-absorbing applications. Polymers 2018, 10, 1180. [CrossRef]

23. Kashi, S.; Gupta, R.K.; Baum, T.; Kao, N.; Bhattacharya, S.N. Morphology, electromagnetic properties and electromagnetic interference shielding performance of poly lactide/graphene nanoplatelet nanocomposites. Mater. Des. 2016, 95, 119-126. [CrossRef]

24. Mensah, E.E.; Abbas, Z.; Azis, R.A.S.; Ibrahim, N.A.; Khamis, A.M. Complex Permittivity and Microwave Absorption Properties of OPEFB Fiber-Polycaprolactone Composites Filled with Recycled Hematite $\left(\alpha-\mathrm{Fe}_{2} \mathrm{O}_{3}\right)$ Nanoparticles. Polymers 2019, 11, 918. [CrossRef] [PubMed]

25. Ravindren, R.; Mondal, S.; Nath, K.; Das, N.C. Synergistic effect of double percolated co-supportive MWCNT-CB conductive network for high-performance EMI shielding application. Polym. Adv. Technol. 2019, 30, 1506-1517. [CrossRef]

26. Aujara, K.M.; Chieng, B.W.; Ibrahim, N.A.; Zainuddin, N.; Thevy Ratnam, C. Gamma-Irradiation Induced Functionalization of Graphene Oxide with Organosilanes. Int. J. Mol. Sci. 2019, 20, 1910. [CrossRef]

27. Liu, P.; Yao, Z.; Zhou, J. Preparation of reduced graphene oxide/Ni0. 4Zn0. 4Co0. 2Fe2O4 nanocomposites and their excellent microwave absorption properties. Ceram. Int. 2015, 41, 13409-13416. [CrossRef]

28. Kristiani, A.; Effendi, N.; Aristiawan, Y.; Aulia, F.; Sudiyani, Y. Effect of combining chemical and irradiation pretreatment process to characteristic of oil palm's empty fruit bunches as raw material for second-generation bioethanol. Energy Procedia 2015, 68, 195-204. [CrossRef] 
29. Harun, N.A.F.; Baharuddin, A.S.; Zainudin, M.H.M.; Bahrin, E.K.; Naim, M.N.; Zakaria, R. Cellulase production from treated oil palm empty fruit bunch degradation by locally isolated Thermobifida fusca. BioResources 2012, 8, 676-687.

30. Wan, Y.J.; Gong, L.X.; Tang, L.C.; Wu, L.B.; Jiang, J.X. Mechanical properties of epoxy composites filled with silane-functionalized graphene oxide. Compos. Part A App. Sci. Manuf. 2014, 64, 79-89. [CrossRef]

31. Sun, C.; Li, C.; Tan, H.; Zhang, Y. Synergistic effects of wood fiber and polylactic acid during co-pyrolysis using TG-FTIR-MS and Py-GC/MS. Energy Convers. Manag. 2019, 202, 112212. [CrossRef]

32. Manoratne, C.H.; Rosa, S.R.D.; Kottegoda, I.R.M. XRD-HTA, UV visible, FTIR and SEM interpretation of reduced graphene oxide synthesized from high purity vein graphite. Mater. Sci. Res. India 2017, 14, 19-30. [CrossRef]

33. Kamatchi, R.; Venkatachalapathy, S.; Srinivas, B.A. Synthesis, stability, transport properties, and surface wettability of reduced graphene oxide/water nanofluids. Int. J. Therm. Sci. 2015, 97, 17-25. [CrossRef]

34. Abdalhadi, D.M.; Abbas, Z.; Ahmad, A.F.; Ibrahim, N.A. Determining the complex permittivity of oil palm empty fruit bunch fibre material by open-ended coaxial probe technique for microwave applications. BioResources 2017, 12, 3976-3991. [CrossRef]

35. Phang, S.W.; Tadokoro, M.; Watanabe, J.; Kuramoto, N. Microwave absorption behaviors of polyaniline nanocomposites containing TiO2 nanoparticles. Curr. Appl. Phys. 2008, 8, 391-394. [CrossRef]

36. Chai, J.; Zhang, D.; Cheng, J.; Jia, Y.; Ba, X.; Gao, Y.; Zhu, L.; Wang, H.; Cao, M. Facile synthesis of highly conductive MoS 2/graphene nanohybrids with hetero-structures as excellent microwave absorbers. RSC Adv. 2018, 8, 36616-36624. [CrossRef]

37. Li, Z.; Sheng, G.; Jiang, X.; Tanaka, T. Effects of inorganic fillers on withstanding short-time breakdown and long-time electrical aging of epoxy composites. IEEJ Trans. Electr. Electron. Eng. 2017, 12, S10-S15. [CrossRef]

38. Kashi, S.; Gupta, R.K.; Bhattacharya, S.N.; Varley, R.J. Experimental and simulation study of effect of thickness on performance of (butylene adipate-co-terephthalate) and poly lactide nanocomposites incorporated with graphene as stand-alone electromagnetic interference shielding and metal-backed microwave absorbers. Compos. Sci. Technol. 2020, 195, 108186.

39. Kashi, S.; Gupta, R.K.; Baum, T.; Kao, N.; Bhattacharya, S.N. Dielectric properties and electromagnetic interference shielding effectiveness of graphene-based biodegradable nanocomposites. Mater. Des. 2016, 109, 68-78. [CrossRef]

40. Maleknejad, Z.; Gheisari, K.; Raouf, A.H. Structure, microstructure, magnetic, electromagnetic, and dielectric properties of nanostructured $\mathrm{Mn}-\mathrm{Zn}$ ferrite synthesized by microwave-induced urea-nitrate process. J. Supercond. Nov. Magn. 2016, 29, 2523-2534. [CrossRef]

41. Zhou, W.; Yu, D. Thermal and dielectric properties of the aluminum particle/epoxy resin composites. J. Appl. Polym. Sci. 2010, 118, 3156-3166. [CrossRef]

42. Ameli, A.; Jung, P.U.; Park, C.B. Electrical properties and electromagnetic interference shielding effectiveness of polypropylene/carbon fiber composite foams. Carbon 2013, 60, 379-391. [CrossRef]

Publisher's Note: MDPI stays neutral with regard to jurisdictional claims in published maps and institutional affiliations.

(C) 2020 by the authors. Licensee MDPI, Basel, Switzerland. This article is an open access article distributed under the terms and conditions of the Creative Commons Attribution (CC BY) license (http://creativecommons.org/licenses/by/4.0/). 